\section{Effect of Heating Fruit on Cell Size and Sugar Accumulation in Melon Fruit (Cucumis melo L.)}

\author{
Yasutaka Kano \\ Ishikawa Prefectural University, Nonoichi, Ishikawa, 921-8836 Japan
}

Additional index words. cell size, sucrose accumulation, high temperature, Cucumis melo

\begin{abstract}
To investigate the relationship between cell size and sugar accumulation, fruit of the melon was heated during the early stage of the growing period. The minimum air temperature in the heating apparatus was $\approx 10{ }^{\circ} \mathrm{C}$ higher than the ambient air temperature, and the weight of the heated fruit was greater than that of the control fruit. The number of rectangular parallelepiped (7-mm-long sample serially collected beginning at one end of the 10 -mm-wide strip removed from the 10 -mm-thick disk at the maximum transverse diameter of the fruit to the opposite end) with cells larger than 200 $\mu \mathrm{m}$ in the heated fruit at 17 days after anthesis (DAA, the end of heating treatment) was much larger that of the control fruit. The mean cell size in the heated fruit at 17 DAA was larger than that of the control fruit. Mean sucrose content of the heated fruit on 40 DAA was larger than the level in the control fruit. Higher fruit temperatures in melons covered with heating apparatus results in the predominance of larger cells and increased accumulation of sucrose in the fruit.
\end{abstract}

Melons are extensively cultivated under plastic film greenhouse from early spring to late fall in Japan. A low Brix value is frequently observed in melon fruit grown during the early spring. The temperature inside the plastic film greenhouse during night falls under $\approx 5{ }^{\circ} \mathrm{C}$ during the early spring. Therefore, a low Brix value of the fruit grown during early spring can be considered to be incited by lower temperature. In this study, cell enlargement and sucrose accumulation are accelerated in the late development of melon fruit, and furthermore, the enlargement and the accumulation are promoted by auxin treatment (Kano, 2002). An increasing number of larger cells and active sucrose accumulation occur in the fruit grown in summer rather than autumn (Kano and Fukuoka, 2006). Therefore, in this report, investigations were carried out regarding cell size and sugar accumulation in melon fruit grown at higher temperature.

\section{Materials and Methods}

Heating apparatus and temperature measurement. As shown in Figure 1, plastic film tubes of $30 \mathrm{~cm}$ in height and $25 \mathrm{~cm}$ in diameter were prepared in which 18-mmcaliber polyvinyl hoses were set so that the air temperature could be controlled $\approx 27{ }^{\circ} \mathrm{C}$. Temperatures inside and outside the heating apparatus for melon fruit, located away from the extremities of the plastic film greenhouse, were measured using a thermo recorder equipped with thermisters called "Ondotori"

Received for publication 29 May 2006. Accepted for publication 5 July 2006.

To whom reprint requests should be addressed; e-mail gansho@ishikawa-c.ac.jp. in Japanese (TR-71S; T and D, Matsumoto, Japan). Temperatures inside the apparatus were measured during the heating period from $3 \mathrm{~d}$ after anthesis (DAA; 23 May) to 17 DAA (6 June). The ambient air temperatures outside the apparatus were measured from 3 DAA to 40 DAA (28 June). Daily maximum and minimum temperatures were illustrated.

Plant materials. Earl's Knight Natsukei No. 2 (Cucumis melo L.) melon seeds were planted on the seed bed on 20 Mar. 2004, and nursery plants were spaced at $40-\mathrm{cm}$ intervals in a plastic film greenhouse on $20 \mathrm{Apr}$. The flowers that opened around on 20 May were used in this experiment. Fruit on the third DAA were held in the heating apparatus (Fig. 1) from 3 DAA to 17 DAA. Three fruit were collected on 17 DAA (the end of heating treatment) and 40 DAA in each treatment, and fruit weights were measured. All three fruit were used for cell and sugar analysis.

Measurements of cell number and size in the fruit. Two disks $\approx 10$-mm thick were excised from each of the three fruit from each treatment, one from the maximum transverse diameter toward the calyx end for cell analysis and one from the maximum transverse diameter toward the peduncle end for sugar analysis. Using a sharp table knife, a sample measuring $\approx 10 \times 10 \mathrm{~mm}$ was removed from the disk with $5 \mathrm{~mm}$ straddling the maximum diameter line across each disk (Fig. 2). Rectangular parallelepipeds (RP), each measuring $7 \mathrm{~mm}$, were serially sampled across the diameter of the disk using the same sharp table knife. Except for the RP containing seeds and the RPs from both ends containing the epidermis, all the RPs along the 7-mm-long strip through the diameter of the fruit body were used. The number of RPs obtained from the control and heated fruit was six and six and eight and eight 17 and 40 DAA, respectively. All of the RPs obtained from fruit from each treatment was dehydrated using various concentrations of alcohol $(70 \%, 80 \%, 90 \%$, and $100 \%)$ before being embedded in paraffin. Seven $10-\mu \mathrm{m}$ thick sections were prepared from these paraffin blocks, and the clearest section from each RP of each treatment was examined under a microscope. As shown in Figure 3, the maximum diameter of individual cells on the maximum transverse diameter in the RPs were measured. Cell size was calculated by dividing total length of cell diameter of each RP of three fruit or all RPs of three fruit by the number of cells of each RP of three fruit or the number of cells of all RPs of three fruit.

Sugar analysis. RPs from the disk taken from the maximum transverse diameter toward the peduncle end were used for sugar analysis. With the exception of the 7-mm RPs containing the seeds and both epidermal layers, all of the RPs were wrapped in cheesecloth and squeezed using pincers to extract the juice. The juice was diluted 10 times with distilled water. The solution was

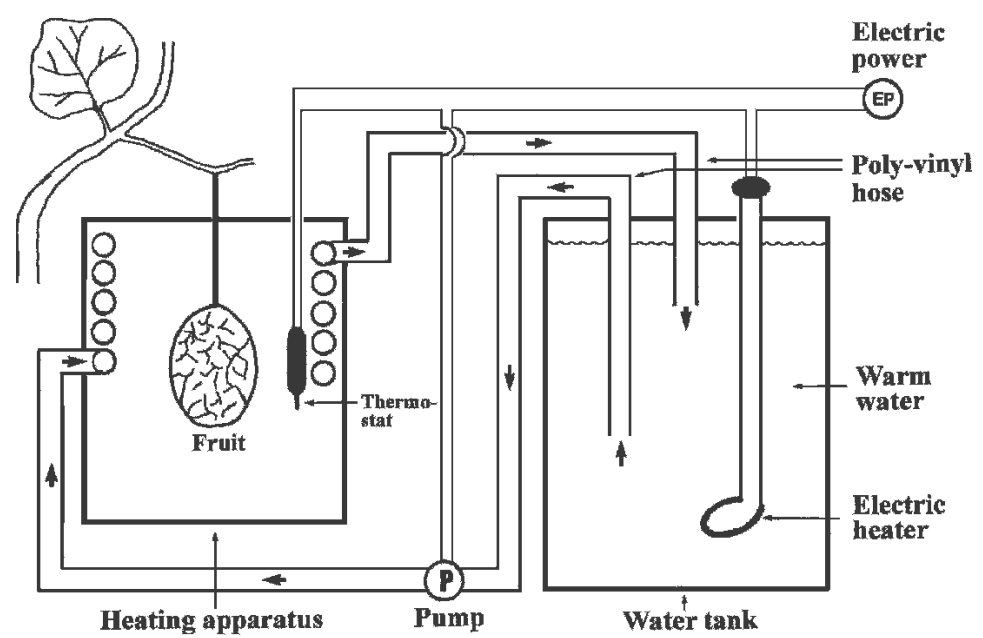

Fig. 1. An illustration of heating apparatus for melon fruit. Warm water was circulated in polyvinyl hose which was set inside the apparatus. Arrows show the flow of warm water. 


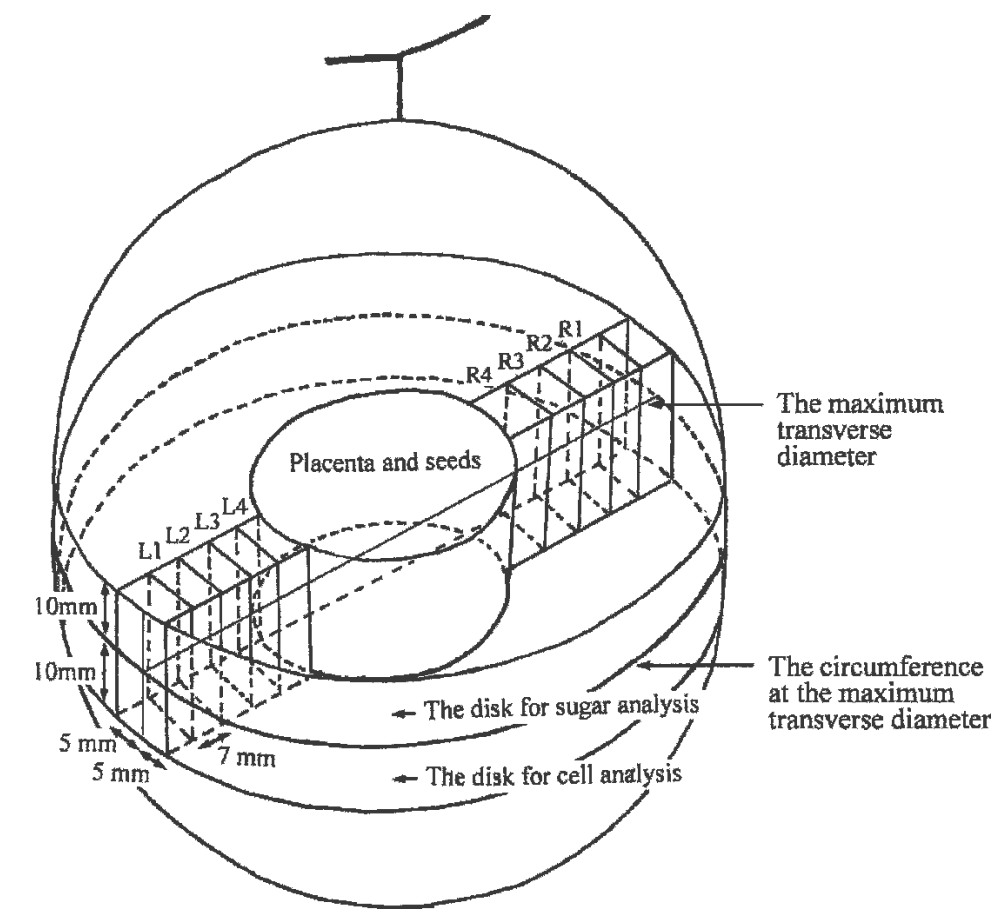

Fig. 2. An illustration of the collection of rectangular parallelepiped parts for the determination of the size and number of cells and sugar content in melon fruit. This is an example for the unheated fruit $40 \mathrm{~d}$ after anthesis.

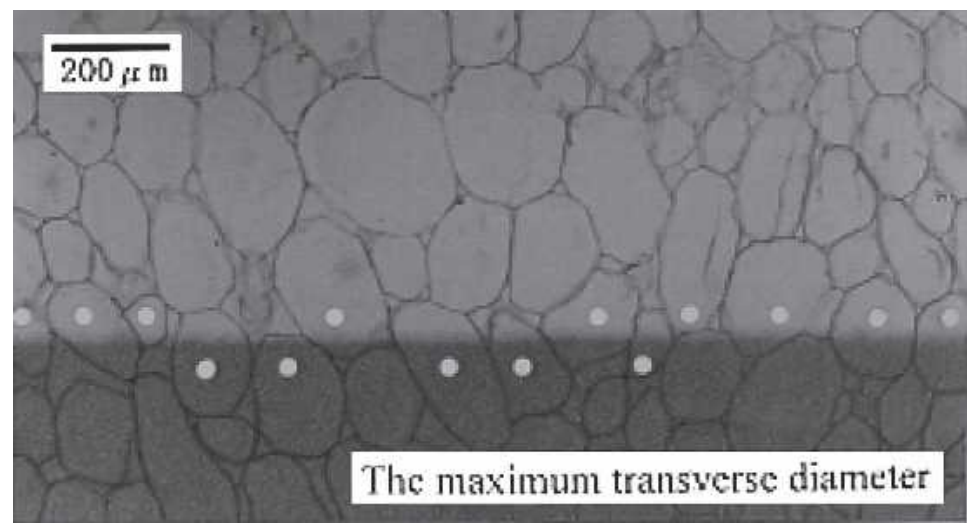

Fig. 3. An illustration of the measurement of the size and the number of cells of melon fruit $40 \mathrm{~d}$ after anthesis. White dots indicate the actual cells measured.

centrifuged at $8000 \times \mathrm{g}$ for $15 \mathrm{~min}$ before being filtered through a $0.45-\mu \mathrm{m}$ filter. Twenty microliters of the filtrate was then injected into high-performance liquid chromatograph (HPLC) (LC-10ADvp; Shimadzu, Japan) fitted with a refractive index detector (RID-10A; Shimadzu Inc.) and equipped with Shim-pack SCR-101C (Shimadzu) at 0.8 $\mathrm{mL} \min ^{-1}$ at $80{ }^{\circ} \mathrm{C}$. Sucrose, glucose, and fructose standards at $20,000 \mathrm{mg} \cdot \mathrm{L}^{-1}$ were injected into the HPLC before injection of the filtrates. Mean sucrose, glucose, and fructose content in each RP was calculated by the dividing total sucrose, glucose, and fructose content of each RP of three fruit by three and mean sucrose, glucose, and fructose content in fruit, by the dividing total sucrose, glucose, and fructose content of all RPs of three fruit by the number of all PRs of three fruit.

\section{Results}

Daily maximum and minimum temperatures in the apparatus were $2.5^{\circ} \mathrm{C}$ and $8.4^{\circ} \mathrm{C}$ higher than the maximum and minimum ambient air temperatures, respectively (Fig. 4). Average weight of the heated fruit at 17 DAA tended to be larger than that of the unheated fruit, but the weight 40 DAA was almost the same in each treatment (Fig. 5).

Although cell diameters of the unheated fruit collected on 17 DAA were distributed over a narrower range centering on $190 \mu \mathrm{m}$, cell diameters of the heated fruit varied markedly (50 $\mu \mathrm{m}$ to $600 \mu \mathrm{m})$ centering on $210 \mu \mathrm{m}$ (Fig. 6). Cell diameters of the unheated fruit on 40 DAA were distributed from $100 \mu \mathrm{m}$ to $400 \mu \mathrm{m}$, but the diameters of the heated fruit were distributed from $100 \mu \mathrm{m}$ to $500 \mu \mathrm{m}$. The number of RPs with mean cell

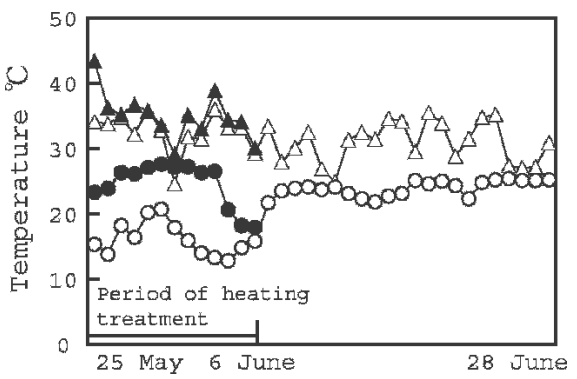

Fig. 4. Comparison of maximum and minimum temperature between the heating apparatus (solid triangle and circle, respectively) and in the open air (empty triangle and circle, respectively).

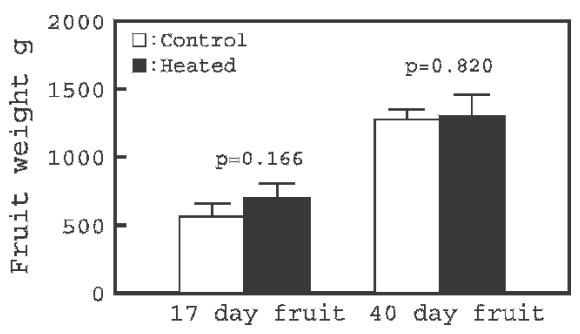

Fig. 5. Effects of heating fruit on the growth of melon fruit. Vertical bars are SD $(n=3)$.

size larger than $200 \mu \mathrm{m}$ on 17 DAA was five in the heated fruit, compared with three in the unheated fruit, and the number of RPs with mean cell size larger than $300 \mu \mathrm{m} 40$ DAA was three in the heated fruit and zero in the unheated fruit (Fig. 7). Mean cell size for all RPs of the heated fruit 17 DAA was $211 \mu \mathrm{m}$, which was significantly different from the size of the unheated fruit, being $191 \mu \mathrm{m}$, but mean cell size of the fruit on 40 DAA was not significantly different between the two treatments (Fig. 7).

A few RPs with smaller than $1.5>20$ $\mathrm{mg} \cdot \mathrm{L}^{-1}$ of sucrose content was recognized in the unheated fruit on 17 DAA, but one in the heated fruit (Fig. 8). The number of RPs with $>20 \mathrm{mg} \cdot \mathrm{L}^{-1}$ on 40 DAA was six in the heated fruit compared with none in the unheated fruit. The number of RPs with higher $23>20$ $\mathrm{g} \cdot \mathrm{L}^{-1}$ of glucose and fructose content was three larger in the heated fruit than in the unheated fruit on 40 DAA. Although mean sucrose, glucose, and fructose content on 17 DAA was smaller in the heated fruit than in the unheated fruit, the mean content on 40 DAA was much greater in the heated fruit than in the unheated fruit (Fig. 8). The level of significance determined by $t$ test for sucrose content between the two treatments on 40 DAA was 0.001 .

\section{Discussion}

Minimum temperatures in the heating apparatus were higher than that of the ambient air temperatures. The weight of the heated fruit was larger than that of the unheated fruit. Fruit weight of melon cv. Earl's Favorite with 

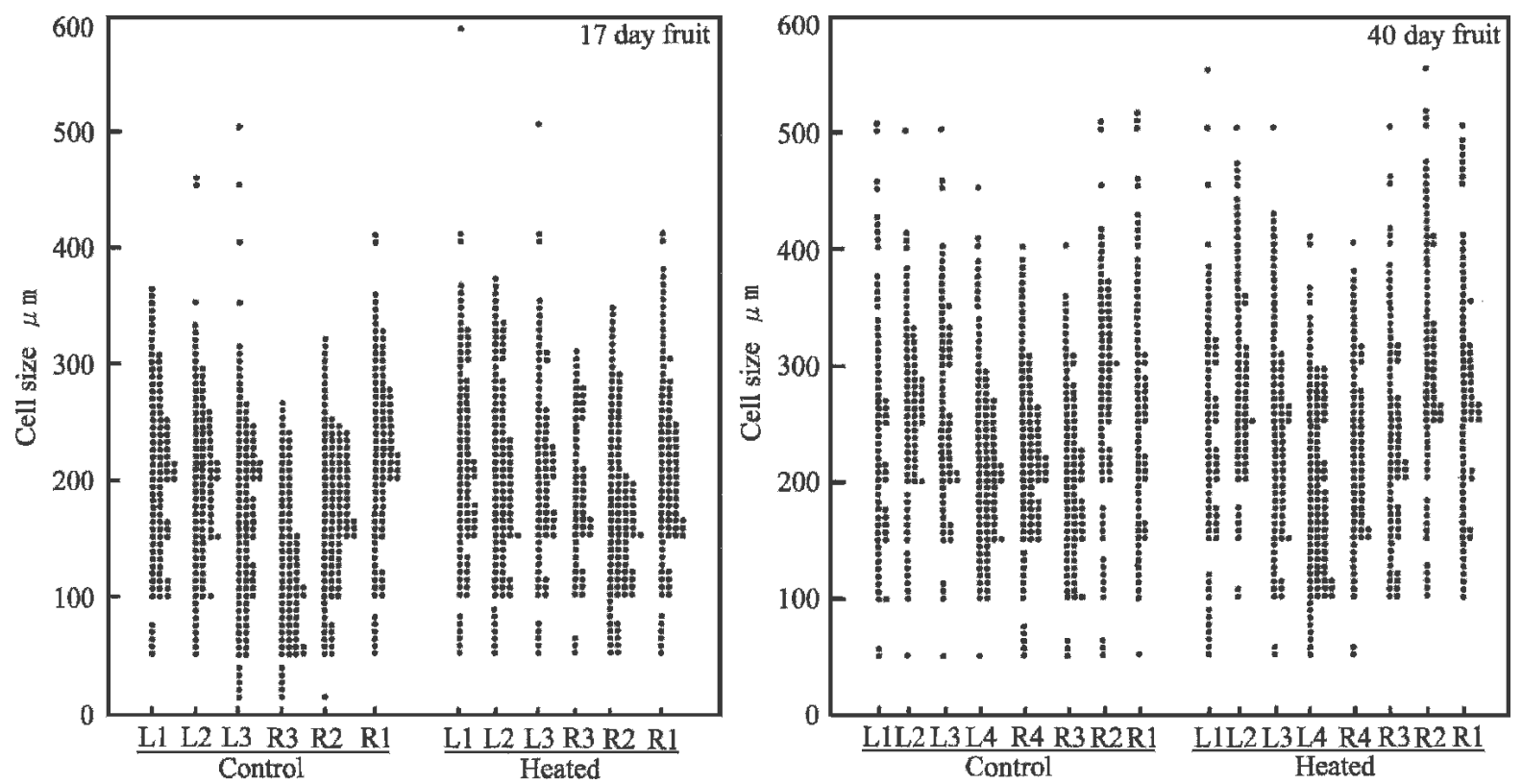

Fig. 6. Effect of heating fruit on the size and the number of cells in each rectangular parallelepiped of the fruit. Refer to Fig. 2 for the symbols under the figures.

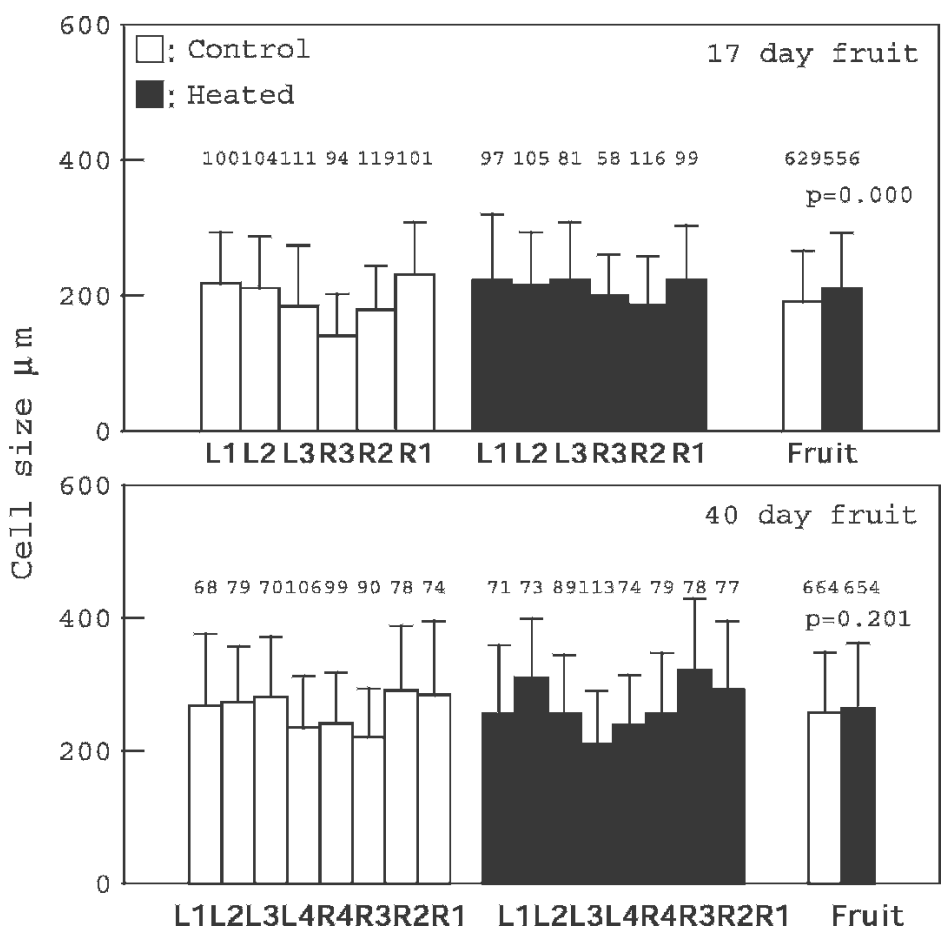

Fig. 7. Effect of heating fruit on the mean size of cells in each rectangular parallelepiped (RP) of the fruit and the fruit. Vertical bars are SD. The numeric values above SD vertical bars are actual number of cells tested. Cell size was calculated by dividing total length of cells in each rectangular parallel-piped of three fruit by total number of cells in each rectangular parallelepiped of three fruit. Refer to Fig. 2 for the symbols under the figures.

anthesis at the beginning of August is larger than that with anthesis at the end of April, and the weight becomes larger with higher night temperatures (Masuda, 1970). Therefore, it is apparent that the growth of melon fruit is accelerated at higher temperatures in a certain temperature range.

Mean cell size of the heated fruit was larger than that of the control fruit. Cells grew larger in melon fruit cv. Earl's Favorite with anthesis on 6 Aug. than in fruit with anthesis on 20 June and grew larger in the higher night temperatures ranging from $10{ }^{\circ} \mathrm{C}$ to $30{ }^{\circ} \mathrm{C}$ (Masuda, 1970). From these results, it can be considered that cells of melon fruit enlarge more actively during the early stage of its development at higher temperature. In other words, the early heating advances cell enlargement, one of the factors related to maturity of the fruit.
Sucrose accumulation both in RPs and in fruit was much more actively promoted in the heated fruit with higher temperatures than in the unheated fruit. Sucrose content is much higher in the fruit of netted melon grown at higher night temperature than in the fruit at lower night temperature (Suzuki et al., 1986). Sucrose accumulation is more accelerated in Japanese pear fruit cv. Nijisseiki grown in warm coastal regions than in cool mountains (Hayashi, 1961) and in Japanese pears grown in places with larger cumulative temperatures (Hiroyasu et al., 1974). Sucrose content was higher in Satsuma mandarin fruits taken from the exterior tree canopy than in fruits taken from the interior (Izumi et al., 1990). These results show that sucrose accumulates actively in fruit that develops in higher temperatures.

Cell enlargement and sucrose accumulation are accelerated in the late development of melon fruit, and furthermore, the enlargement and accumulation are promoted by auxin treatment (Kano, 2002). The small vacuoles of meristematic cells increase in size and gradually coalesce as the cells enlarge and age (Esau, 1964). Most of the imported sugars accumulate in the vacuole of sink-tissue storage cells (Leigh et al., 1979; Yamaki and Ino, 1992). The mean cell volume of strawberry fruit increases slowly during active cell division but rises rapidly and linearly for $10 \mathrm{~d}$ after cell division is halted (Guiwen and Breen, 1992). Sucrose content in the vacuole of strawberry fruit increases from 25 to 35 DAA (Ofosu-Anim and Yamaki, 1994). With these results in mind, it is reasonable to consider that the content of sucrose accumulated in the cells of melon fruit increases due to the coalescence and enlargement of vacuoles by cell enlargement.

From these results, the following conclusions can be made. Cell size increases in the 


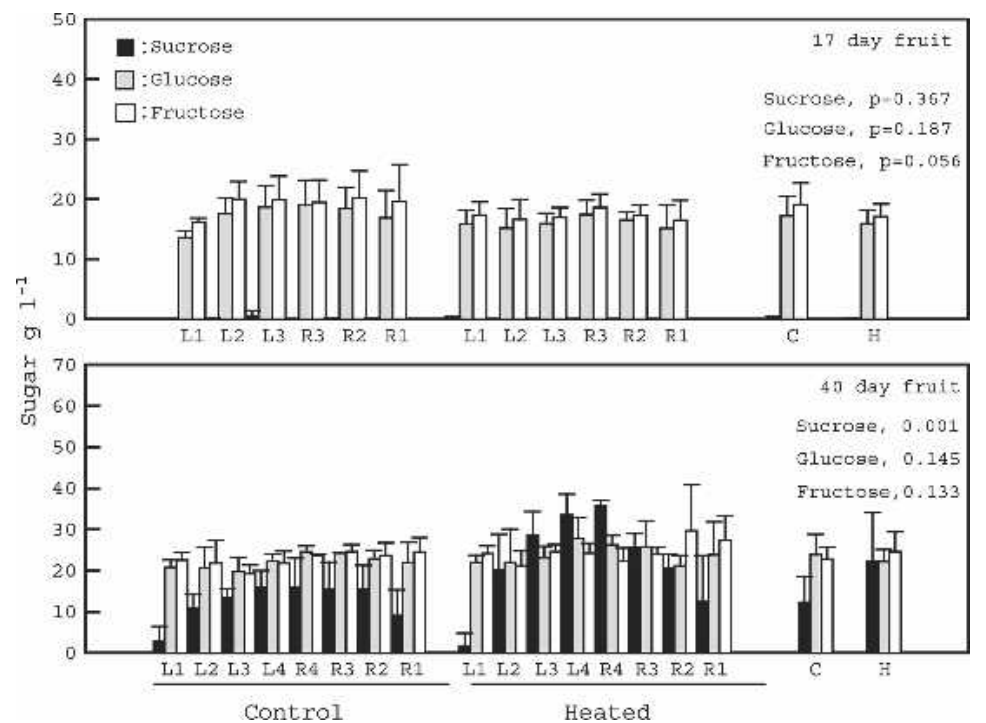

Fig. 8. Effect of heating fruit on sugar content in each rectangular parallelepiped (RP) of the fruit and in the fruit. Vertical bars are SD ( $\mathrm{n}=3$ for each RP; $\mathrm{n}=17$ and 24 for 17 and 40 fruits, respectively). The values for each RP were calculated by dividing the content of each sugar in three rectangular parallelepipeds by 3 . Refer to Fig. 2 for the symbols under the figures. The values for fruit were calculated by dividing total sugar content of all RP of three fruit by total number of RPs of three fruit. $\mathrm{C}$, control; $\mathrm{H}$, heated.

early stage of the fruit development in the heated fruit owing to high temperature. Sucrose begins to accumulate actively with the progress of cell enlargement. Because the period from the time of the beginning of sucrose accumulation to $40 \mathrm{DAA}$ is much longer in the heated fruit than in the unheated fruit, the content of the heated fruit results in higher sucrose content.
Hiroyasu, T., H. Ishii, and B.-N. Duone. 1974 Variation in sugar and organic acid content in grape and Japanese pear fruits produced in different localities Tech. Bull. Fac. Hort. Chiba Univ. 22:41-47.

Izumi, H., T. Ito, and Y. Yoshida. 1990. Sugar and ascorbic acid contents of Satsuma mandarin fruits harvested from exterior and interior canopy of trees during fruit development. J. Jpn. Soc. Hort. Sci. 58: 877-883.

Kano, Y. 2002. Relationship between sucrose accumulation and cell size in 4-CPA-treated melon fruits (Cucumis melo L.). J. Hort. Sci. Biotechnol. 77:546-550.

Kano, Y. and N. Fukuoka. 2006. Comparison of cell size and sugar accumulation in melons (Cucumis melo L.) grown early and late in summer. Environ. Control Biol. 44:93-102.

Leigh, R.A., T. Apree, W.A. Fuler, and J. Bonfield. 1979. The location of acid invertase and sucrose in vacuoles isolated from storage roots of red beet (Beta vulgaris L.). Biochem. J. 178:53-57.

Masuda, T. 1970. Studies on the development of melon fruits, $\mathrm{PhD}$ Thesis, Kyoto Univ., Kyoto, Japan.

Ofosu-Anim, J. and S. Yamaki. 1994. Sugar content, compartmentation, and efflux in strawberry tissue. J. Amer. Soc. Hort. Sci. 119:10241028.

Suzuki, T., S. Nakamura, M. Toda, and A. Ozawa. 1986. Temperature and humidity control in growing of glasshouse muskmelon. Bul. Shizuoka Agr. Expt. Sta. 31:47-54.

Yamaki, S. and M. Ino. 1992. Alteration of cellular compartmentation and membrane permeability to sugars in immature and mature apple fruit. J. Amer. Soc. Hort. Sci. 17: 951-954. 